\title{
Personalized Medicine Applied to Forensic Sciences: New Advances and Perspectives for a Tailored Forensic Approach
}

\author{
Alessandro Santurro ${ }^{1}$, Anna Maria Vullo ${ }^{1}$, Marina Borro ${ }^{2}$, Giovanna Gentile $^{2}$, Raffaele La Russa ${ }^{1,3}$, \\ Maurizio Simmaco ${ }^{2}$, Paola Frati ${ }^{1,3, *}$ and Vittorio Fineschi ${ }^{1,4}$ \\ ${ }^{I}$ Department of Anatomical, Histological, Forensic and Orthopaedic Sciences, Sapienza University of Rome, Viale Re- \\ gina Elena 336, 00185 Rome, Italy; ${ }^{2}$ Department of Neurosciences, Mental Health and Sensory Organs, Sapienza Uni- \\ versity of Rome, Via di Grottarossa 1035, 00189 Rome, Italy; ${ }^{3}$ Malzoni Clinical-Scientific Institute (MaCSI), Via Car- \\ melo Errico 2, 83100 Avellino, Italy; ${ }^{4}$ IRCCS Neuromed, Via Atinense 18, 86077 Pozzilli, Italy
}

\begin{abstract}
Personalized medicine (PM), included in P5 medicine (Personalized, Predictive, Preventive, Participative and Precision medicine) is an innovative approach to the patient, emerging from the need to tailor and to fit the profile of each individual. PM promises to dramatically impact also on forensic sciences and justice system in ways we are only beginning to understand. The application of omics (genomic, transcriptomics, epigenetics/imprintomics, proteomic and metabolomics) is ever more fundamental in the so called "molecular autopsy". Emerging fields of interest in forensic pathology are represented by diagnosis and detection of predisposing conditions to fatal thromboembolic and hypertensive events, determination of genetic variants related to sudden death, such as congenital long QT syndromes, demonstration of lesions vitality, identification of biological matrices and species diagnosis of a forensic trace on crime scenes without destruction of the DNA. The aim of this paper is to describe the state-of-art in the application of personalized medicine in forensic sciences, to understand the possibilities of integration in routine investigation of these procedures with classical post-mortem studies and to underline the importance of these new updates in medical examiners' armamentarium in determining cause of death or contributing factors to death.
\end{abstract}

Keywords: Personalized medicine, Forensic Sciences, Theragnostic, Molecular Autopsy, Genomics, Transcriptomics, Proteomics, Pharmacogenomics, Metabolomics, Sudden death.

\section{INTRODUCTION}

\subsection{Personalized Medicine and Molecular Autopsy}

Personalized medicine (PM), included in so called P4 medicine (Personalized, Predictive, Preventive and Participative medicine), besides a fifth $\mathrm{P}$ represented by emerging Precision medicine initiative, is an innovative approach to the patient, in a comprehensive effort integrated in the common frame of P5 medicine. As a result, rather than accepting the one-size-fits-all, the need to be tailored to fit the profile of each individual patient is an emerging practice [1]. In this way, new approaches are critical to adapt clinical treatment to the individual and to propose available alternatives taking into account the specific profile of the person. In other words, clinical practice, by translation of the general advances in scientific knowledge and implementation of new diagnostics, can finally and successfully lead to tailoring and

*Address correspondence to this author at the Department of Anatomical, Histological, Forensic and Orthopaedic Sciences, Sapienza University of Rome, Viale Regina Elena 336, 00185 Rome, Italy; Tel: +39 06 49912622; Fax:+39 06 4455335; E-mail: paola.frati@uniroma1.it;

paola.frati@fastwebnet.it personalization, offering better-targeted diagnosis and treatments (diagnostic and therapeutic - also together "theragnostic"). Theragnostics, in fact, is a treatment strategy that combines therapeutics with diagnostics, associating diagnostic tests that identify patients to be helped by a medication, and targeted drug therapy based on the test results [2]. The final aim is to develop efficient targeted therapies with adequate benefit/risk to patients and a better molecular understanding of how to optimize drug appropriateness-efficacy-safety, monitoring the response to the treatment and eliminating the unnecessary ones.

On the other hand, even if clinical acceptance has been proven as slow and all these clinical applications seem actually entangled, PM promises to dramatically impact also the justice system in ways we are only beginning to understand. It is clear that the application of personalized medicine in the practice of law, in general, and in the autopsy practice, in particular, is of great medico-legal interest and may have potential legal consequences [3]. Moreover, PM's forensic pathology ramifications are evident and, as an analogue of PM, a new essential aspect of this approach has emerged, so called personalized justice (PJ) as application of post-mortem 
PM in medico-legal investigation [4]. In fact, besides classic forensic tools such as toxicology, histology and imaging, new ones include genomic, transcriptomics, epigenetics/ imprintomics, proteomic and metabolomics (so called "omics") [5-7]. The application of omics is ever more fundamental to investigate basis, causes and processes of death at the molecular level in the so called "molecular autopsy". These innovative forensic procedure, hand in hand with the advances in medical sciences, are important to promote scientific interpretation and evidence-based assessment of individual deaths.

\subsection{Emerging Fields of Interest in Forensic Pathology}

Molecular forensic pathology involves the application of medical sciences and all the available ancillary procedures for comprehensive assessment and complete interpretation of forensic matters [8]. Furthermore, experimental and practical investigations in molecular autopsy, i.e. molecular biological procedures derived from omic sciences in the context of forensic pathology, are usefulness in detecting basis, causes and mechanisms involved in the death process. These updated procedures may effectively be included in routine investigation in combination with classical post-mortem diagnostic procedures, for a comprehensive assessment of the human death process, investigating this processes at a molecular level, as a useful resource in the determination of causes and manners of death, especially in unexpected sudden deaths [9-11].

In addition to the identification of biological materials on the crime scene, lastly these procedures may also contribute to estimating the time of death and post-mortem interval (PMI), which is another major interest in forensic pathology, even if limited to cases in the early post-mortem period without evident decomposition.

\subsection{Role of Omics}

In molecular forensic pathology, the individual genetic set (genome), the regulation of gene expression (transcriptome) and the complement of genes' products (proteome), are becoming, time after time, fundamental matters in order to investigate causes and manners of death.

In this way, omic sciences are bringing promising results. In particular, genomic and SNP (single nucleotide polymorphism) study is useful in the diagnosis and detection of predisposing conditions to fatal thromboembolic and hypertensive events, and in the determination of genetic variants related to sudden death, such as congenital long QT syndromes. On the other hand, transcriptomic and miRNAs analysis is useful to demonstrate vitality of lesions; as long as proteomic approach presents many applications in pathology forensic, in particular in forensic investigations on crime scenes, for the identification of a biological matrix and the species of origin of a forensic trace without destruction of the DNA.

\section{GENOMICS}

Genomics is the systematic study of genome, the total DNA containing 3.2 billion bases, with an estimated 30.000 40.000 protein-coding genes and a variability of genetic material between any two individuals approximately $1 \%$. These genetic variations can be classified into four classes:
- VNTR (variable number of tandem repeat);

- $\quad$ STR (short tandem repeat);

- SNP (single nucleotide polymorphism, including restriction fragment length polymorphism);

- $\quad \mathrm{CNV}$ (copy-number variation).

The most common variations in DNA sequences are single nucleotide polymorphisms (SNPs), changes in a single base at a specific position in the genome, and in most cases with two alleles, found at a frequency of about 1:1000 bases. It is possible to distinguish:

- SNPs in non-coding regions, altering the DNA sequence of promoter, introns or 3'-untraslated region; these changes may result in deregulation of gene expression affecting the amount or the structure of the encoded protein;

- SNPs in coding regions, altering the DNA sequence of exons. Such nucleotide substitutions are called synonymous (no change of amino acid in the protein, but can affect stability of the transcript) or non-synonymous substitutions. Non-synonymous substitutions can be missense, if the change results in a different amino acid in the protein sequence (thus affecting protein functionality) or non-sense, if the change introduces a stop codon, causing a truncated and usually non-functional protein product.

Being the most frequent and studied type of genetic interindividual variance, SNPs detection actually represents the heart of PM [12-19]. The importance of SNPs in forensic molecular pathology relies on the ability to recognize a genetic predisposition to a condition which causes or contributes to death, as in the cases (described below) of risk assessment of fatal thromboembolic and hypertensive events, and in the determination of genetic variants related to sudden death, such as congenital long QT syndromes.

Moreover, SNP profiling appears useful to establish the individual predisposition to suffer from adverse reaction, including lethal ones to drug intake. The role played by SNPs and other genetic variants in drug metabolism is studied by pharmacogenomics (PGx). Variations in genes coding for drug targets, drug metabolizing enzymes and drug transporters are known to affect the susceptibility to both therapeutic and toxic effect of medication and other xenobiotics. Thus, also conventional dose consumption may lead to drug overload or to enhanced drug elimination (impairing therapeutic effect), both conditions possibly involved in adverse events causing death [20-22].

Technologies for SNPs analysis range from low throughput platforms, e.g. allowing characterization of one or few SNPs per run, as RFLP analysis, real-time PCR, pyrosequencing, to medium and high throughput assays, e.g. allowing analyses of tens to hundreds SNPs per run, as MALDIToF(matrix-assisted laser/desorption ionization-time of flight) mass spectrometry, microarray and next generation sequencing. Several SNP genotyping technologies facilitate rapid testing performed by automated platforms, some with FDA - Center for Devices and Radiological Health (CDRH) approval [23] (Table 1). 
Table 1. List of Human Genetic Tests approved by CDRH - FDA US.

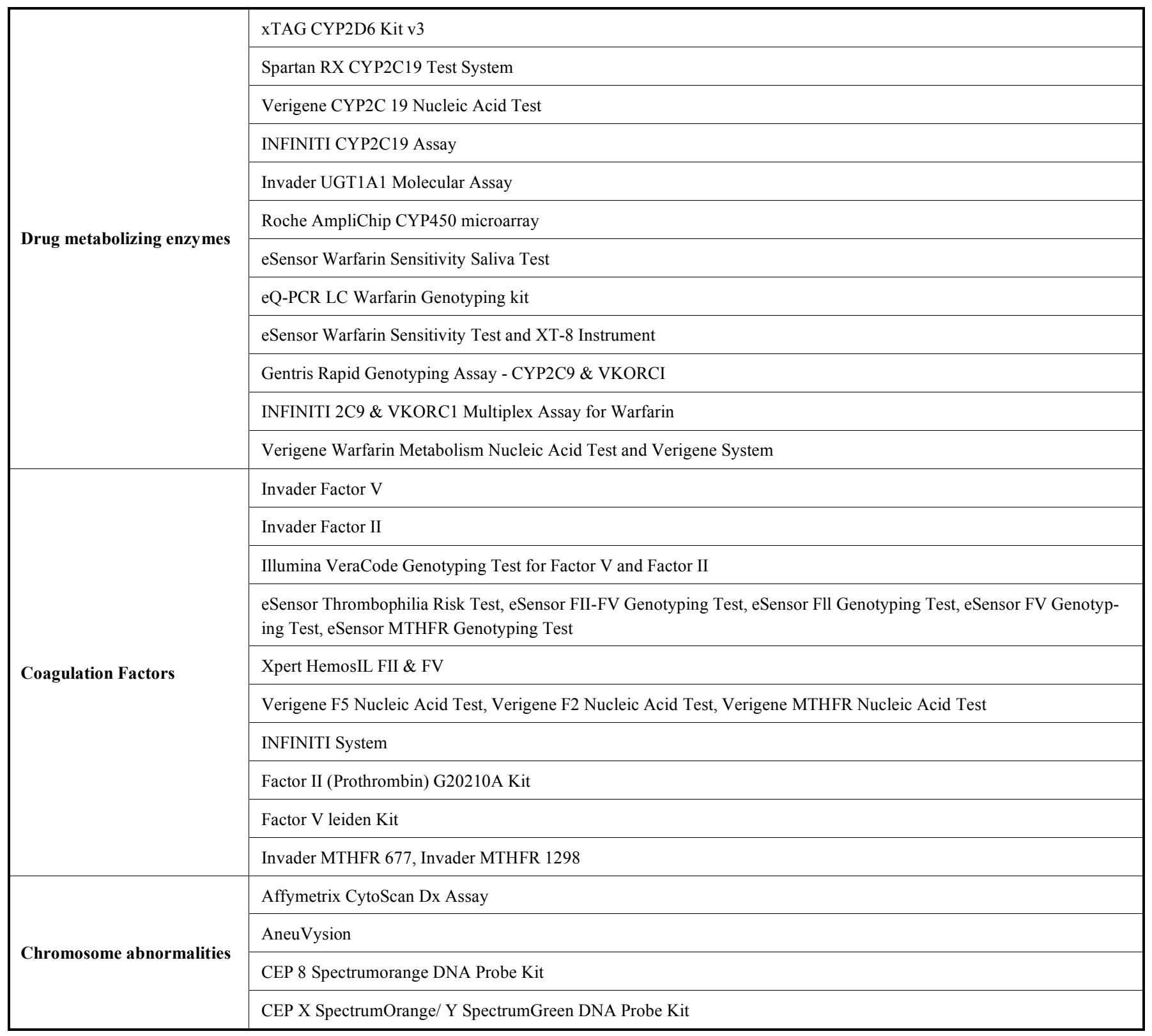

\subsection{Risk Assessment of Fatal Thromboembolic and Hy- pertensive Events}

Venous thromboembolism (VTE), with its main manifestations - deep venous thromboembolism (DVT) and fatal pulmonary embolism (PE) -, is a multifactorial disease and is among the most common causes of natural unexpected death. Most deaths are associated with the three predisposing factors described by Virchow: stasis, hypercoagulability and vascular injury. In particular, hypercoagulability risk factors include thrombophilic diseases or conditions associated with an increased thrombotic risk.

The association between several SNPs and an increased individual risk for developing venous thromboembolism has been widely described and VTE-associated SNPs are in- creasingly been employed to improve risk assessment of patients [24].

In forensics, a molecular pathology approach aimed to characterize the genomic risk of VTE is useful to improve the comprehension of basis, causes and mechanisms involved in the death process involving thromboembolic events, according to an evidence-based approach to death assessment [25-28].

It is noteworthy to note that the identification of a genomic profile contributing to a lethal VTE event may prompt the decedent's relatives to check their own genomic profile and global VTE risk, warning for the onset of appropriate prevention strategies and thus avoiding a recurring tragedy within family [29-30]. 
Table 2. Polymorphisms involved in thrombophilic risk.

\begin{tabular}{|c|c|c|c|}
\hline & Gene Name & Chromosomal Location & Mutation/SNP Researched \\
\hline \multirow{6}{*}{ 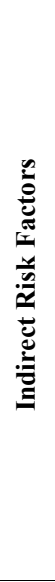 } & \multirow{2}{*}{$\begin{array}{l}\text { Methylenetetrahydrofolate reductase } \\
\text { (MTHFR) }\end{array}$} & \multirow{2}{*}{$1 \mathrm{p} 36.22$} & $\begin{array}{l}\text { MTHFR C677T } \\
\text { (rs1801133) }\end{array}$ \\
\hline & & & $\begin{array}{l}\text { MTHFR A1298C } \\
\quad(\mathrm{rs} 1801131)\end{array}$ \\
\hline & \multirow{2}{*}{$\begin{array}{l}\text { Cystathionine beta synthase } \\
\text { (CBS) }\end{array}$} & \multirow{2}{*}{$21 \mathrm{q} 22.3$} & $\begin{array}{l}\text { CBS C699T } \\
(\mathrm{rs} 234706)\end{array}$ \\
\hline & & & $\begin{array}{l}\text { CBS T1080C } \\
(\text { rs5742905) }\end{array}$ \\
\hline & $\begin{array}{l}\text { Methionine synthase } \\
\text { (MTR) }\end{array}$ & $1 \mathrm{q} 43$ & $\begin{array}{l}\text { MTR A2756G } \\
(\text { rs1805087) }\end{array}$ \\
\hline & $\begin{array}{l}\text { Methionine Synthase Reductase } \\
\text { (MS_MTRR) }\end{array}$ & $5 \mathrm{p} 15.31$ & $\begin{array}{l}\text { MS_MTRR A66G } \\
\text { (rs1801394) }\end{array}$ \\
\hline \multirow{6}{*}{ 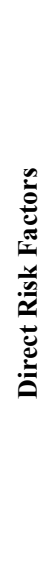 } & \multirow{2}{*}{$\begin{array}{l}\text { Factor V } \\
\text { (F5) }\end{array}$} & \multirow{2}{*}{$1 \mathrm{q} 24.2$} & $\begin{array}{l}\text { F5L G1691A } \\
\quad(\mathrm{rs} 6025)\end{array}$ \\
\hline & & & $\begin{array}{l}\text { F5 G1764A } \\
(\text { rs6030) }\end{array}$ \\
\hline & $\begin{array}{l}\text { Prothrombin - Factor II } \\
\text { (PT) }\end{array}$ & $11 \mathrm{p} 11.2$ & $\begin{array}{l}\text { PT G20210A } \\
\text { (rs1799963) }\end{array}$ \\
\hline & $\begin{array}{c}\text { Plasminogen activator inhibitor-1 } \\
\text { (PAI-1) }\end{array}$ & $7 \mathrm{q} 22.1$ & $\begin{array}{l}\text { PAI-1 }-675(4 \mathrm{G} / 5 \mathrm{G}) \\
\quad(\mathrm{rs} 1799889)\end{array}$ \\
\hline & $\begin{array}{l}\text { Fibrinogen beta chain } \\
\text { (FGB) }\end{array}$ & $4 q 31.3$ & $\begin{array}{l}\text { FGB G455A } \\
(\mathrm{rs} 1800790)\end{array}$ \\
\hline & $\begin{array}{l}\text { Factor XIII A1 chain } \\
\text { (F13A1) }\end{array}$ & $6 \mathrm{p} 25.1$ & $\begin{array}{l}\text { F13A1 Val34Leu } \\
\quad(\text { rs5895) }\end{array}$ \\
\hline
\end{tabular}

Table 2 reports the main SNPs associated with increased risk of thrombophilia and having an important causal relevance in causation of death [31-33]. Factor V Leiden, prothrombin or factor II (PT), plasminogen activator inhibitor-1 (PAI-1), fibrinogen beta chain (FGB) and factor XIII A1 chain (F13A1) are particularly relevant since their alteration is considered a direct risk factor and their activity can be assessed also post-mortem.

On the other hand, the polymorphisms in the genes encoding for methylenetetrahydrofolate reductase (MTHFR), cystathionine beta synthase (CBS), methionine synthase (MTR), methionine synthase reductase (MS_MTRR), represent indirect risk factors for thromboembolism (by decreased enzyme activity and hyperhomocysteinemia) and thus are less relevant.

For example, the SNPs of MTHFR gene, rs1801133 also known as MTHFR C677T or A222V - and rs1801131 also known as MTHFR A1298C or E429A - have as a result a more thermolabile enzyme, determining an activity reduced by $50 \%$, that results in clinical phenotype with mild hyperhomocysteinemia, especially in nutritional deficiency of folic acid, with increased risk of cerebrovascular (stroke) and cardiovascular (myocardial infarction) events and venous thrombosis. However, the genetic risk factor may be counterbalanced with opportune therapy and dietary regimen, modifying the levels of homocysteine that however cannot be assessed in post-mortem, so that cannot be considered a major (direct) risk factor [34, 35].

Instead, polymorphisms in FV Leiden and Prothrombin Factor II genes are thought to be a major risk factor for thromboembolic events. The Factor $\mathrm{V}$ gene polymorphism known as Leiden mutation (rs6025, also termed F5L or $\mathrm{G} 1691 \mathrm{~A}$ ) is found in 3 to $5 \%$ of the individuals. Risks for venous thromboembolism for $(\mathrm{A} ; \mathrm{G})$ and $(\mathrm{A} ; \mathrm{A})$ genotypes are $2.7 \mathrm{x}$ and $18 \mathrm{x}$, respectively; overall, patients heterozygotes for both Leiden and prothrombin SNP rs1799963 (also known as PT G20210A) have a higher risk of recurrent thrombosis, and depending on other factors (oral contraceptives, estrogen-progestogen therapy, pregnancy, surgical events or fractures, other prothrombotic disorders such as SLE, malignancy, ATIII deficiency, protein $\mathrm{C}$ or protein S), this risk can climb to at least $5 \mathrm{x}$ [36].

Other important SNPs raising the risk of developing venous thromboembolism are:

- Plasminogen activator inhibitor-1 PAI-1 gene insertion/deletion results in increased plasma levels of PAI-1 (inhibitor of tPA) in homozygous carriers (4G/4G, 26\% of the population); 
- Fibrinogen beta chain FGB G455A polymorphism increases the blood concentration of beta fibrinogen;

- Factor XIII A1 chain gene Val34Leu polymorphism determines high concentrations of fibrinogen and increased permeability of the clot.

All these predisposing conditions result in greater risk of thrombosis, both arterial (myocardial infarction, coronary artery disease and youth cryptogenic cerebral stroke) and venous, complicated or not as thromboembolism, especially in smokers and hypertensives, mainly in the presence of environmental risk factors trigger such as: long assets, fractures, surgeries, estrogen-progestogen therapy (oral contraceptive, replacement therapy in menopause). During pregnancy, this can cause various complications (such as miscarriage, preeclampsia, foetal growth retardation, abruptio placentae).

According to these premises, genotyping is indicated in:

- All patients who experience events of venous thromboembolism, especially those younger (age $<50$ years) with unusual site of thrombosis (hepatic, mesenteric or cerebral), or who have recurrent thrombotic events;

- All women who experience complications of pregnancy and those which, in the presence of a positive family history, must take estrogen-progestogen therapy;

- Asymptomatic individuals who have a first-degree carrier of the mutation.

On the other hand, hypertension being one of the main risk factors for coronary disease, and hence also for sudden death, is $3 \mathrm{x}$ higher in patients with moderate hypertension than in normotensives, so in hypertensives, sudden cardiac death constitutes $27-60 \%$ of all cardiovascular deaths.

Gene polymorphisms predisposing to the development of hypertension have been described, the most important affecting the genes coding for angiotensinogen (AGT), angiotensin II receptor type 1 (AGTR1), angiotensin converting enzyme (ACE) and integrin beta 3 (ITGB3 - HPA-1) (Table 3) [37, 38].

SNPs in AGT gene have been implicated in risk for hypertension and related disorders, such as heart disease and pre-eclampsia. In particular, patients with the mutated allele
(C;T, C;C) of the SNP rs699 (also known as AGT T9543C) have a risk about $3 \mathrm{x}$ of developing cardiovascular diseases, whereas carriers of the polymorphic variant rs4762 (also known as AGT C9369T) have a greater risk of developing cardiovascular diseases and a $1.9 \mathrm{x}$ risk for pre-eclampsia $[39,40]$.

AGTR1 gene is quite polymorphic, with over 50 described SNPs affecting susceptibility to hypertension and related disorders, such as heart disease, as well as resistance to antihypertensive drugs. Polymorphism rs5186, also known as AGTR1 A1166C, in hypertensive patients correlates with increased aortic stiffness, risk of stroke and acute myocardial infarction [41-43].

The insertion (I)/deletion (D) variant in the ACE gene can influence the degree to which individuals respond to ACE-inhibitors and the cardiovascular risk (hypertension, left ventricular hypertrophy, acute myocardial infarction at a young age and acute coronary syndrome in postmenopausal) for ID and DD genotype is 5x and 10x, respectively [44].

At last, the ITGB3 gene polymorphism T1565C is associated with a high risk of hypercoagulation, resulting in venous thrombotic complications [45].

\subsection{Congenital Long QT Syndromes, Antipsychotics and Sudden Cardiac Death Diagnosis}

Congenital long QT syndromes (LQTS) can arise from mutation of one of several genes and can be inherited in an autosomal dominant or recessive phenotype. Subsequently, QT interval is a heritable trait in healthy subjects and detecting genetic variants is important for determining people at higher risk from drugs that cause QT prolongation.

Non-drug and environmental factors regulators of QT are female gender (because of shorter early repolarization and testosterone effects on calcium current), electrolyte disturbance (hypocalcaemia and hyperkalaemia), hypoglycaemia) and increasing age. QT prolongation is also associated with different pharmacological therapies, such as antipsychotics (in particular quetiapine, olanzapine, clozapine, sertindole, haloperidol and chlorpromazine), antidepressants (clomipramine and amitriptyline, citalopram) and mood stabilizers (lithium), but not associated with anxiolytic agents. The risk of QT-prolonging is plasma concentration-related and depends on drug elimination (pharmacokinetic interactions) [46].

Table 3. Polymorphisms panel for hypertensive genomic profile.

\begin{tabular}{|c|c|c|}
\hline Gene Name & Chromosomal Location & Mutation/SNP Researched \\
\hline \multirow{2}{*}{$\begin{array}{l}\text { Angiotensinogen } \\
\text { (AGT) }\end{array}$} & \multirow{2}{*}{$1 \mathrm{q} 42.2$} & $\begin{array}{l}\text { AGT T9543C } \\
\quad(\text { rs699) }\end{array}$ \\
\hline & & $\begin{array}{l}\text { AGT C9369T } \\
(\text { rs4762) }\end{array}$ \\
\hline $\begin{array}{c}\text { Angiotensin II receptor type } 1 \\
\text { (AGTR1) }\end{array}$ & $3 q 24$ & $\begin{array}{l}\text { AGTR1 A1166C } \\
(\text { rs5186) }\end{array}$ \\
\hline $\begin{array}{c}\text { Angiotensin converting enzyme } \\
\text { (ACE1) }\end{array}$ & $17 \mathrm{q} 23.3$ & $\begin{array}{l}\mathrm{ACE} 1 \mathrm{I} / \mathrm{D} \\
(\mathrm{rs} 1799752)\end{array}$ \\
\hline $\begin{array}{c}\text { Integrin beta } 3 \text { - HPA-1 - GPIIIa } \\
\text { (ITGB3) }\end{array}$ & $17 \mathrm{q} 21.32$ & $\begin{array}{l}\text { ITGB3 T1565C } \\
\text { (rs5918) }\end{array}$ \\
\hline
\end{tabular}


In particular, drug administration can induce Torsades de Pointes (diTdP), a specific form of ventricular arrhythmia, sustained by inhibition of the output currents of potassium channel $\mathrm{I}_{\mathrm{Kr}}$ and by block of inner currents of sodium and calcium. Variants of LQTS may contribute to susceptibility for diTdP in a percentage on average around 5-10\% of subjects. Identification of these cases emphasizes the emerging role of preventive medicine [47-58].

Fifteen different genetic mutations in ion channel subunits (potassium and sodium channels) and in regulatory protein have been identified (Table 4) [53-58].

LQTS1, known as Jervell and Lange-Nielsen syndrome, is the most common form of LQST, representing 30-35\% of all cases. The gene responsible is KCNQ1, which encodes alpha subunit of slow delayed rectifier potassium voltagegated channel $\left(\mathrm{K}_{\mathrm{V}} 7.1\right)$. SNPs in KCNQ1 gene cause marked prolongation of the QT interval (due to the almost complete loss of $\mathrm{I}_{\mathrm{Kr}}$ current), and an increased risk of ventricular arrhythmias and congenital deafness. LQTS1 is less often associated with sudden death compared to LQTS2, so it is one of the less severe forms of LQTS.

LQTS2 is the second most common variant, representing $25-30 \%$ of all cases and involving hERG gene, which encodes alpha subunit of rapid delayed rectifier potassium voltage-gated channel $\left(\mathrm{K}_{\mathrm{V}} 11.1\right)$, part of the potassium rapid rectifying current $\left(\mathrm{I}_{\mathrm{Kr}}\right)$. Most of the drugs that cause LQT block $\mathrm{I}_{\mathrm{Kr}}$ current via hERG gene.

LQTS3 is determined by mutations in SCN5A gene, which encodes alpha-5 subunit of sodium voltage-gated channel $\left(\mathrm{Na}_{\mathrm{V}} 1.5\right)$. Calcium has been suggested as a regulator of SCN5A protein.

Most updated and current studies investigate the relationship of polymorphisms and variable risk for TdP. Between the discovered SNPs, the most common ones giving rise to alleles predisposing to LQTS are SCN5A Ser1103Tyr and KCNQ1 Ala341Val.

SCN5A Ser1103Tyr (rs7626962) is the most common polymorphism $(\sim 13 \%$ allelic frequency in African Americans), involving alpha-5 subunit of sodium voltage-gated channel $\left(\mathrm{Na}_{\mathrm{V}} 1.5\right)$ and determining increased late sodium current especially under acidosis conditions, with susceptibility to acidosis-induced arrhythmia and increased risk for sudden infant death syndrome [59,60].

KCNQ1 Ala341Val (rs12720459) represents one of the most common variants within the KCNQ1 gene leading to LQT1, the most frequent form of LQTS [61].

This variant meets ACMG 2013 criteria regarding incidental findings in exome or genome sequencing, as a variant that they do recommend informing a patient about. In particular, ACMG recommends the opportunity to re-evaluate the patient's personal and family history and consider appropriate surveillance or intervention for patients and their family members who are deemed to be at increased risk for these conditions.

\section{TRANSCRIPTOMICS}

Transcriptomics is the study of the RNA present in the cell and thus analyses the panel of genes actively expressed.
MicroRNAs (miRNAs) are small endogenous non-coding single-stranded RNA molecules $\sim 22$ nucleotides long that can transcriptionally and post-transcriptionally regulate gene expression, interacting with almost $30 \%$ of the coding genes. In particular miRNAs, assembled into the RNA-induced silencing complex (RISC), bind to their target messenger RNAs (mRNAs) in 3' UTR, leading to mRNA degradation and blocking translation.

miRNAs have tissue-specific patterns of expression, are highly conserved across mammalian species and related to several diseases (cancer, diabetes, cardiovascular disease), becoming attractive therapeutic targets. miRNAs are increasingly used in forensic pathology, in particular to demonstrate tissue or cell vitality in skin lesions [62-64].

\subsection{Determination of Vitality and Age of Skin Lesions and Wounds}

Study of miRNAs in the determination of the healing processes, and therefore, of formation time of a possible skin lesion, is an emerging practice in forensic pathology.

The repair process of damaged skin involves three phases: inflammatory, proliferative (epithelialization, angiogenesis, granulation and collagen deposition) and remodelling phase. During this process, changes take place in the expression of specific miRNAs at a specific phase of wound healing. Many miRNAs have been proposed as targets of investigation in the dating of the skin lesions. The most important are reported in Table 5 .

- Inflammation response to wound is tightly regulated by pro-inflammatory as well as anti-inflammatory signals. miRNAs are responsive and regulate some inflammatory mediators in the course of wound healing. In particular, miR-21, miR-146a/b and miR-155 play a key role. miR-146 and miR-155 are induced by TNF- $\alpha$ and IL-1 $\beta$, while miR-2 1 is induced by IL-6. miR-21 target are PTEN and PDCD4, miR-146 targets are IRAK and COX2, while miR155 target are SHIP1, SOCS1, and IL-12 [65, 66].

- Proliferation is characterized by epithelialization, angiogenesis, granulation and collagen deposition, and is influenced by hypoxia and hypoxia-sensitive miRNA (known as hypoxamiRs). miRNA-210, under control of hypoxia-regulated genes Hif-1 $\alpha$ and Hif-2 $\alpha$, is the most sensitive to hypoxia; on the other hand, miR-210 silences some key proteins like E2F3 which is required for keratinocyte proliferation. Some of the most well-characterized miRNA-regulated proteins involved in proliferation are Spred1 (miR-126), c-kit (miR-221/222), Tsp-1 (miR-17-92), ITGA5 (miR-92a), VEGF (miR-20a) and TIMP-1 (miR-17-5p) [67, 68].

- Remodelling phase is characterized by collagen deposition, and several miRNAs contribute to this phase, in particular miRNA-29b, miRNA-29c, and miRNA-192. MiRNA-29b and miR-29c targets are Smads and $\beta$-catenin, involved in scarless healing, while miR-192 target is Smad-interacting protein 1 (SIP1) [69]. 
Table 4. SNPs involved in congenital long QT syndromes.

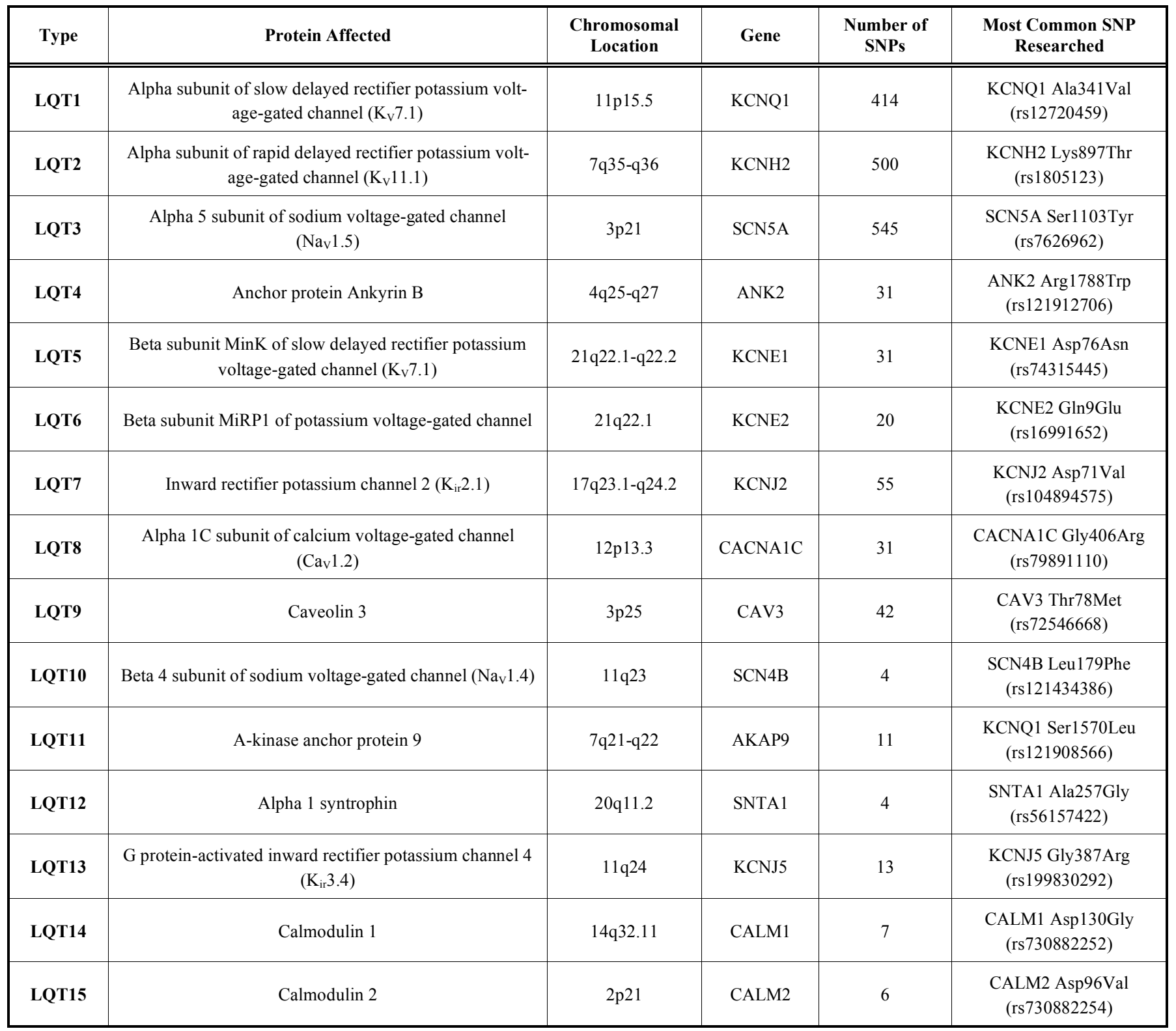

\section{PROTEOMICS}

Proteome is the set of all expressed proteins $(>100.000$ proteins) in a specific cell and in a specific stage, reflecting both genes expression and environment influence, thus holding special promise for biomarker discovery because of the ubiquitously involvement in pathological processes [70].

The main advantage of proteomics markers compared to genomic and transcriptomics markers is that they are more closely related to the actual phenotype.

Proteomic approach presents many applications in forensic pathology, in particular in forensic investigations on crime scenes, for the identification of biological matrices and the origin species of a forensic trace without destruction of the DNA [71].

\subsection{Detection of Biological Specimens on the Crime Scene}

Proteomic-based approach has been developed to identify protein on the crime scene (blood, seminal fluid, saliva and lacrimal fluid). Even if proteins are less stable than DNA, the most remarkable advantage of this approach is to not be destructive, by the first washing step of DNA extraction, thus saving most of the sample for subsequent DNA analysis [72].

The proteomic approach ranges from identification of single proteins by immunohistochemistry to simultaneous identification of multiple protein signatures using mass spectrometry technology as MALDI, surface-enhanced laser desorption/ionisation (SELDI), capillary liquid chromatography coupled to tandem mass spectrometry (LC-MS/MS). 
Table 5. Key miRNAs involved in different phases of wound healing.

\begin{tabular}{|c|c|c|}
\hline Phase & MicroRNA & Target \\
\hline \multirow{5}{*}{ Inflammatory } & $\operatorname{miR}-140$ & PDGF receptor \\
\hline & miR-146 & IRAK, COX2 \\
\hline & miR-147 & IgG Fc $\gamma \mathrm{RI}(\mathrm{CD} 64)$ \\
\hline & miR-155 & SHIP1, SOCS1, IL12 \\
\hline & $\operatorname{miR}-424$ & PU.1, NFI-A \\
\hline \multirow{8}{*}{ Proliferative } & miR-15b, miR-16, miR-20a, miR-20b & VEGF \\
\hline & miR-92a & Integrin-alfa5 \\
\hline & miR-126 & Spred1, PIK3R2 \\
\hline & miR-130a & GAX, HOXA5 \\
\hline & miR-184 & Akt \\
\hline & $\operatorname{miR}-205$ & SHIP2, Rho-ROCK1 \\
\hline & $\operatorname{miR}-210$ & EFNA3, E2F3, ISCU 1/2 \\
\hline & miR-221, miR-222 & c-kit \\
\hline Remodelling & miR-192 & SIP1 \\
\hline
\end{tabular}

Scientific investigations on biological traces occurring on a crime scene are usually carried out through a series of sequential steps, involving generic, species, regional and individual diagnosis. All these steps together allow the investigators to reconstruct the dynamics of the criminal event and to check the reliability of assertions by putative suspect people [73-75]. In particular, in generic and species diagnosis, proteomic procedures can be applied:

- Generic diagnosis: consists of the identification of real nature of the trace (saliva, blood, semen and lacrimal fluid) by using preliminary and confirmatory tests. Preliminary tests include luminol or benzidine for blood, ultraviolet light or other light sources at specific wavelengths for semen and saliva. Confirmatory tests are essentially based on immunochemical techniques or ELISA methods, detecting prostate-specific antigen (PSA) in semen, alpha-amylase 1 in saliva and alpha-amylase 2, in semen and vaginal secretion.
- Species diagnosis: consists of the determination of species of the donor of trace found at a crime scene. Previously performed by highly specific antibodies on blood and on hair by microscopic examination, new MS-based proteomic procedures have been introduced to obtain species diagnosis and the identification of human body fluids or tissues. Most important protein markers of species diagnosis detected by capillary LC-MS/MS are reported in Table 6.

This proteomic approach has many advantages such as the possibility to identify proteins by their fragments, high specificity of tissue localization and high sensitivity of LCMS/MS. Instead, disadvantages arising from the intrinsic nature of biological traces to be analysed are represented by easy degradation of biological matrices, low variability so that no individual diagnosis is possible, no possibility of amplification and quantity problems [76-78]. 
Table 6. Protein markers in biological matrices for species diagnosis.

\begin{tabular}{|c|c|}
\hline Matrices & Protein Markers \\
\hline \multirow{8}{*}{ Blood } & Haemoglobin Alpha-subunit (HBA) \\
\hline & Haemoglobin Beta-subunit (HBB) \\
\hline & Band 3 anion transport protein (SLC4A1) \\
\hline & Alpha-Haemoglobin-Stabilizing Protein (AHSP) \\
\hline & Glycophorin-A (GLYA) \\
\hline & Porphobilinogen deaminase (PBGD) \\
\hline & Alpha-spectrin (SPTA1) \\
\hline & Beta-spectrin (SPTB) \\
\hline Sweat & Dermcidin (DCD) \\
\hline \multirow{4}{*}{$\begin{array}{l}\text { Lacrimal } \\
\text { fluid }\end{array}$} & Lacrimal proline-rich protein 4 (LPRR4) \\
\hline & Lacrimal Androgen-binding protein delta (LABPD) \\
\hline & Lacrimal Androgen-binding protein zeta (LABPZ) \\
\hline & Extracellular glycoprotein lacritin (LACRT) \\
\hline \multirow{7}{*}{ Saliva } & Alpha-amylase 1 (AMY1) \\
\hline & Histatin-1 (HTN1) \\
\hline & Histatin-3 (HTN3) \\
\hline & Basic salivary proline-rich protein 2 (PRB2) \\
\hline & Statherin (STATH) \\
\hline & Mucin-5B (MUC5B) \\
\hline & Cystatin SA (CST2) \\
\hline Urine & Uromodulin (UMOD) \\
\hline \multirow{3}{*}{$\begin{array}{c}\text { Menstrual } \\
\text { blood }\end{array}$} & Matrix metalloprotease 7 (MMP7) \\
\hline & Matrix metalloprotease 10 (MMP10) \\
\hline & Matrix metalloprotease 11 (MMP11) \\
\hline \multirow{7}{*}{$\begin{array}{l}\text { Vaginal } \\
\text { fluid }\end{array}$} & Mucin 4 isoform A (MUC4) \\
\hline & Human Beta-Defensin 1 (HBD1) \\
\hline & Small Proline-Rich Protein 3 (SPRP3) \\
\hline & Dimethylaniline Monooxygenase 3 (FMO3) \\
\hline & Cartilage Intermediate Layer Protein (CILP) \\
\hline & Beta-Crystallin S (CRYGS) \\
\hline & A-Kinase Anchor Protein 13 Isoform 1 (AKAP13) \\
\hline \multirow{11}{*}{$\begin{array}{l}\text { Seminal } \\
\text { fluid }\end{array}$} & Semenogelin-1 (SEMG1) \\
\hline & Semenogelin-2 (SEMG2) \\
\hline & Prostate-Specific Antigen (PSA) \\
\hline & Prostatic acid phosphatase (PAP) \\
\hline & Mucin 6 (MUC6) \\
\hline & Kallikrein 4 (KLK4) \\
\hline & Protamine 1 (PRM1) \\
\hline & Protamine 2 (PRM2) \\
\hline & Progestogen-Associated Endometrial Protein (PAEP) \\
\hline & Cysteine-Rich Secretory Protein 1 (CRISP1) \\
\hline & Transglutaminase 4 (TGM4) \\
\hline
\end{tabular}

\section{CONCLUSION}

Application of omic sciences to investigate the processes of death at a biological molecular level in the context of forensic pathology is an emerging practice. The aim to visualize molecular evidence for a general explanation of the human death involving forensic issues, as well as for the assessment of individual death, makes this new approach even more fundamental. The new opportunities, offered by omics, are of considerable interest to forensic scientists. So that, these procedures have been and will even be more in the coming decades incorporated in routine death investigations. This new challenge in forensic research has, in fact, become an increasingly important tool in medical examiners' armamentarium in determining cause of death or contributing factors to death.

For example, understanding the genetic component of the common disease, coupled with the use of molecular genetic testing, has become an increasingly important issue. The most recent advances in "molecular autopsies" have begun to uncover the mystery surrounding sudden unexplained natural deaths by identifying mutations that can result in or predispose an apparently healthy individual to sudden death. Although a relatively novel concept in the forensic context, omic sciences have the capability to assist in the interpretation of deaths. Advanced diagnostic analyses, genetic counselling, and interdisciplinary and multidisciplinary approach, should be integral parts of forensic practice.

In this way, the ability to identify underlying cause of death, especially in genetic disorders, not only allows the determination of cause of death in a decedent, but may also help in avoiding a recurring tragedy within family. Large population data and large-scale clinical trials can provide a powerful resource for assessing the inherent risk, providing an opportunity to investigate genomic associations and common inherited variations in the individuals. So on, postmortem human data can also contribute to understanding patients' critical conditions in clinical management. The potential to improve the clinical practice is only at the very beginning but will present an important biomedical tool in the omic era.

\section{CONFLICT OF INTEREST}

The author(s) confirm that this article content has no conflict of interest.

\section{ACKNOWLEDGEMENTS}

Declared none.

\section{AUTHORS' ROLES}

All authors contributed equally to manuscript drafting and critical discussion and approved the final version.

\section{REFERENCES}

[1] Borro, M.; Simmaco, M.; Aceti, A.; Barni, S.; De Luca, A.; Fineschi, V.; Frati, P.; Girardi, P.; Miozzo, M.; Nati, G.; Nicoletti, F.; Santini, D.; Marchetti, P. H2020 and Beyond: Skip Discrepancy between Theory and Practice of Personalized Medicine. A Position Paper by the Italian Society of Personalized Medicine. Curr. Pharm. Biotechnol., 2016, 17, 926-929. 
[2] Pene, F.; Courtine, E.; Cariou, A.; Mira, J.P. Toward theragnostics. Crit. Care Med., 2009, 37, S50-58.

[3] Wong, S.H.Y.; Happy, C. Personalized justice, translational pharmacogenomics and personalized medicine - relevant to the forensic sciences? Tox. Talk, 2009, 33, 22-23.

[4] Wong, S.H.; Happy, C.; Blinka, D.; Gock, S.; Jentzen, J.M.; Donald Hon, J.; Coleman, H.; Jortani, S.A.; Lucire, Y.; MorrisKukoski, C.L.; Neuman, M.G.; Orsulak, P.J.; Sander, T.; Wagner, M.A.; Wynn, J.R.; Wu, A.H.; Yeo, K.T. From personalized medicine to personalized justice: the promises of translational pharmacogenomics in the justice system. Pharmacogenomics, 2010, 11, 731-737.

[5] Westerhoff, H.V.; Palsson, B.O. The evolution of molecular biology into systems biology. Nat. Biotechnol., 2004, 22, 1249-1252.

[6] Baraldi, E.; Carraro, S.; Bozzetto, S.; Reniero, F.; Giordano, G. The omic sciences: a platform for the customized medicine. Minerva Pediatr., 2009, 61, 618-620.

[7] Evans, G.A. Designer science and the "omic" revolution. Nat. Biotechnol., 2000, 18, 127.

[8] Madea, B.; Saukko, P.; Oliva, A.; Musshoff, F. Molecular pathology in forensic medicine - introduction. Forensic Sci. Int., 2010, 203, 3-14.

[9] Maeda, H.; Zhu, B.L.; Ishikawa, T.; Michiue, T. Forensic molecular pathology of violent deaths. Forensic Sci. Int., 2010, 203, 8392.

[10] Tester, D.J.; Ackerman, M.J. The role of molecular autopsy in unexplained sudden cardiac death. Curr. Opin. Cardiol., 2006, 21, $166-172$

[11] de la Grandmaison, G.L. Is there progress in the autopsy diagnosis of sudden unexpected death in adults? Forensic Sci. Int., 2006, 156, 138-144.

[12] Schneider, P.M. Scientific standards for studies in forensic genetics. Forensic Sci. Int., 2007, 165, 238-43.

[13] Karch, S.B. Changing times: DNA resequencing and the nearly normal autopsy. J. Forensic Leg. Med., 2007, 14, 389-397.

[14] Giardina, E.; Pietrangeli, I.; Martone, C.; Zampatti, S.; Marsala, P.; Gabriele, L.; Ricci, O.; Solla, G.; Asili, P.; Arcudi, G.; Spinella, A.; Novelli, G. Whole genome amplification and real-time PCR in forensic casework. BMC Genomics, 2009, 10, 159.

[15] De Wit, P.; Pespeni, M.H.; Palumbi, S.R. SNP genotyping and population genomics from expressed sequences - current advances and future possibilities. Mol. Ecol., 2015, 24, 2310-2323.

[16] Sobrino, B.; Brión, M.; Carracedo, A. SNPs in forensic genetics: a review on SNP typing methodologies. Forensic Sci. Int., 2005, 154, 181-194.

[17] Divne, A.M.; Allen, M. A DNA microarray system for forensic SNP analysis. Forensic Sci. Int., 2005, 154, 111-121.

[18] Li, H. Systems genetics in "-omics" era: current and future development. Theory Biosci., 2013, 132, 1-16.

[19] Lam, C.W.; Lau, K.C.; Tong, S.F. Microarrays for personalized genomic medicine. Adv. Clin. Chem., 2010, 52, 1-18.

[20] Ma, Q.; Lu, A.Y. Pharmacogenetics, pharmacogenomics and individualized medicine. Pharmacol. Rev., 2011, 63, 437-459.

[21] Evans, W.E.; Relling, M.V. Moving towards individualized medicine with pharmacogenomics. Nature, 2004, 429, 464-468.

[22] Kell, D.B. Systems biology, metabolic modelling and metabolomics in drug discovery and development. Drug Discov. Today, 2006, $11,1085-1092$.

[23] U.S. Food and Drug Administration. Nucleic Acid Based Tests. http://www.fda.gov/MedicalDevices/ProductsandMedicalProcedure s/InVitroDiagnostics/ucm330711.htm (Accessed Feb 2, 2017).

[24] Baglin, T. Using the laboratory to predict recurrent venous thrombosis. Int. J. Lab. Hematol., 2011, 33, 333-342.

[25] van Hylckama Vlieg, A.; Baglin, C.A.; Bare, L.A.; Rosendaal, F.R.; Baglin, T.P. Proof of principle of potential clinical utility of multiple SNP analysis for prediction of recurrent venous thrombosis. J. Thromb. Haemost., 2008, 6, 751-754.

[26] Cohn, D.M.; Roshani, S.; Middeldorp, S. Thrombophilia and venous thromboembolism: implications for testing. Semin. Thromb. Hemost., 2007, 33, 573-581.

[27] van Hylckama Vlieg, A.; Flinterman, L.E.; Bare, L.A.; Cannegieter, S.C.; Reitsma, P.H.; Arellano, A.R.; Tong, C.H.; Devlin, J.J.; Rosendaal, F.R. Genetic variations associated with recurrent venous thrombosis. Circ. Cardiovasc. Genet., 2014, 7, 806-813.

[28] de Haan, H.G.; Bezemer, I.D.; Doggen, C.J.; Le Cessie, S.; Reitsma, P.H.; Arellano, A.R.; Tong, C.H.; Devlin, J.J.; Bare, L.A.;
Rosendaal, F.R.; Vossen, C.Y. Multiple SNP testing improves risk prediction of first venous thrombosis. Blood, 2012, 120, 656-663. van Hylckama Vlieg, A.; Flinterman, L.E.; Bare, L.A.; Cannegieter, S.C.; Reitsma, P.H.; Arellano, A.R.; Tong, C.H.; Devlin, J.J.; Rosendaal, F.R. Genetic variations associated with recurrent venous thrombosis. Circ. Cardiovasc. Genet., 2014, 7, 806-813

[30] Berezovskiǔ, D.P.; Varavva, T.A.; Faleeva, T.G.; Pigolkin, Iu.I. Kornienko, I.V. Forensic medical evaluation of hereditary predisposition to thrombophilia in the case of thrombotic complications of a mechanical injury. Sud. Med. Ekspert., 2014, 57, 22-25.

[31] Couturaud, F.; Leroyer, C.; Tromeur, C.; Julian, J.A.; Kahn, S.R.; Ginsberg, J.S.; Wells, P.S.; Douketis, J.D.; Mottier, D.; Kearon, C. Factors that predict thrombosis in relatives of patients with venous thromboembolism. Blood, 2014, 124, 2124-2130.

[32] De Stefano, V.; Rossi, E. Testing for inherited thrombophilia and consequences for antithrombotic prophylaxis in patients with venous thromboembolism and their relatives. A review of the Guidelines from Scientific Societies and Working Groups. Thromb. Haemost., 2013, 110, 697-705.

[33] Soria, J.M.; Morange, P.E.; Vila, J.; Souto, J.C.; Moyano, M.; Trégouët, D.A.; Mateo, J.; Saut, N.; Salas, E.; Elosua, R. Multilocus genetic risk scores for venous thromboembolism risk assessment. J. Am. Heart Assoc., 2014, 3, e001060.

[34] Brezovska-Kavrakova, J.; Krstevska, M.; Bosilkova, G.; Alabakovska, S.; Panov, S.; Orovchanec, N. Hyperhomocysteinemia and of Methylenetetrahydrofolate Reductase (C677T) Genetic Polymorphism in Patients with Deep Vein Thrombosis. Mater. Sociomed., 2013, 25, 170-174.

[35] Roach, R.E.; Cannegieter, S.C.; Lijfering, W.M. Differential risks in men and women for first and recurrent venous thrombosis: the role of genes and environment. J. Thromb. Haemost., 2014, 12, 1593-1600.

[36] Chegeni, R.; Kazemi, B.; Hajifathali, A.; Pourfathollah, A.; Lari, G.R. Factor V mutations in Iranian patients with activated protein C resistance and venous thrombosis. Thromb. Res., 2007, 119, 189193.

[37] Hu, D.C.; Zhao, X.L.; Shao, J.C.; Wang, W.; Qian, J.; Chen, A.H.; Zhang, H.Q.; Guo, H.; Jiang, J.; Li, H.Y. Interaction of six candidate genes in essential hypertension. Genet. Mol. Res., 2014, 13, 8385-8395.

[38] Petkeviciene, J.; Klumbiene, J.; Simonyte, S.; Ceponiene, I.; Jureniene, K, Kriaucioniene, V.; Raskiliene, A.; Smalinskiene, A.; Lesauskaite, V. Physical, behavioural and genetic predictors of adult hypertension: the findings of the kaunas cardiovascular risk cohort study. PLoS One, 2014, 9, e109974.

[39] Martínez, E.; Puras, A.; Escribano, J.; Sanchis, C.; Carrión, L.; Artigao, M.; Divisón, J.A.; Massó, J.; Fernández, J.A. Threonines at position 174 and 235 of the angiotensinogen polypeptide chain are related to familial history of hypertension in a SpanishMediterranean population. Br. J. Biomed. Sci., 2002, 59, 95-100.

[40] Olivieri, O.; Stranieri, C.; Girelli, D.; Pizzolo, F.; Grazioli, S.; Russo, C.; Pignatti, P.F.; Corrocher, R. Homozygosity for angiotensinogen $235 \mathrm{~T}$ variant increases the risk of myocardial infarction in patients with multi-vessel coronary artery disease. J. Hypertens., 2001, 19, 879-884

[41] Kim, H.K.; Lee, H.; Kwon, J.T.; Kim, H.J. A polymorphism in AGT and AGTR1 gene is associated with lead-related high blood pressure. J. Renin Angiotensin Aldosterone Syst., 2015, 16, 712719.

[42] Salminen, L.E.; Schofield, P.R.; Pierce, K.D.; Conturo, T.E.; Tate, D.F.; Lane, E.M.; Heaps, J.M.; Bolzenius, J.D.; Baker, L.M.; Akbudak, E.; Paul, R.H. Impact of the AGTR1 A1166C polymorphism on subcortical hyperintensities and cognition in healthy older adults. Age (Dordr.), 2014, 36, 9664.

[43] Zhang, K.; Zhou, B.; Zhang, L. Association study of angiotensin II type 1 receptor:A1166C (rs5186) polymorphism with coronary heart disease using systematic meta-analysis. J. Renin Angiotensin Aldosterone Syst., 2013, 14, 181-188.

[44] Zhao, J.; Qin, X.; Li, S.; Zeng, Z. Association between the ACE I/D polymorphism and risk of ischemic stroke: An updated metaanalysis of 47,026 subjects from 105 case-control studies. $J$. Neurol. Sci., 2014, 345, 37-47.

[45] Zotova, T.Iu.; Miandina, G.I.; Frolov, V.A.; Komarova, A.G.; Zotov, A.K. The influence of ITGB3 gene polymorphism on the frequency of arterial hypertension in patients with acute coronary syndrome. Klin. Med. (Mosk), 2013, 91, 22-24. 
[46] van Noord, C.; Eijgelsheim, M.; Stricker, B.H. Drug- and nondrug- associated QT interval prolongation. Br. J. Clin. Pharmacol., 2010, 70, 16-23.

[47] Newton-Cheh, C.; Larson, M.G.; Corey, D.C.; Benjamin, E.J.; Herbert, A.G.; Levy, D.; D’Agostino, R.B.; O’Donnell, C.J. QT interval is a heritable quantitative trait with evidence of linkage to chromosome 3 in a genome-wide linkage analysis: The Framingham Heart Study. Heart Rhythm, 2005, 2, 277-284.

[48] Ramirez, A.H.; Shaffer, C.M.; Delaney, J.T.; Sexton, D.P.; Levy, S.E.; Rieder, M.J.; Nickerson, D.A.; George, A.L.; Roden, D.M. Novel rare variants in congenital cardiac arrhythmia genes are frequent in drug-induced torsades de pointes. Pharmacogenomics J., 2013, 13, 325-329.

[49] Jagu, B.; Charpentier, F.; Toumaniantz, G. Identifying potential functional impact of mutations and polymorphisms: linking heart failure.; increased risk of arrhythmias and sudden cardiac death. Front. Physiol., 2013, 4, 254.

[50] Priori, S.G.; Aliot, E.; Blømstrom-Lundqvist, C.; Bossaert, L.; Breithardt, G.; Brugada, P.; Camm, J.A.; Cappato, R.; Cobbe, S.M.; Di Mario, C.; Maron, B.J.; McKenna, W.J.; Pedersen, A.K.; Ravens, U.; Schwartz, P.J.; Trusz-Gluza, M.; Vardas, P.; Wellens, H.J.; Zipes, D.P; European Society of Cardiology. Task Force sulla morte cardiaca improvvisa; Società Europea di Cardiologia. Ital. Heart J. Suppl., 2002, 3, 1051-1065.

[51] Kannankeril, P.J.; Roden, D.M. Drug-induced long QT and torsade de pointes: recent advances. Curr. Opin. Cardiol., 2007, 22, 39-43.

[52] Titier, K.; Girodet, P.O.; Verdoux, H.; Molimard, M.; Bégaud, B.; Haverkamp, W.; Lader, M.; Moore, N. Atypical antipsychotics: from potassium channels to torsade de pointes and sudden death. Drug Saf., 2005, 28, 35-51.

[53] Behr, E.R.; Ritchie, M.D.; Tanaka, T.; Kääb, S.; Crawford, D.C.; Nicoletti, P.; Floratos, A.; Sinner, M.F.; Kannankeril, P.J.; Wilde, A.A.; Bezzina, C.R.; Schulze-Bahr, E.; Zumhagen, S.; Guicheney, P.; Bishopric, N.H.; Marshall, V.; Shakir, S.; Dalageorgou, C.; Bevan, S.; Jamshidi, Y.; Bastiaenen, R.; Myerburg, R.J.; Schott, J.J.; Camm, A.J.; Steinbeck, G.; Norris, K.; Altman, R.B.; Tatonetti, N.P.; Jeffery, S.; Kubo, M.; Nakamura, Y.; Shen, Y.; George, A.L. Jr.; Roden, D.M. Genome wide analysis of drug-induced torsades de pointes: lack of common variants with large effect sizes. PLoS One, 2013, 8, e78511.

[54] Pfeufer, A.; Jalilzadeh, S.; Perz, S.; Mueller, J.C.; Hinterseer, M.; Illig, T.; Akyol, M.; Huth, C.; Schöpfer-Wendels, A.; Kuch, B.; Steinbeck, G.; Holle, R.; Näbauer, M.; Wichmann, H.E.; Meitinger, T.; Kääb, S. Common variants in myocardial ion channel genes modify the QT interval in the general population: results from the KORA study. Circ. Res., 2005, 96, 693-701.

[55] Kannankeril, P.J.; Roden, D.M. Drug-induced long QT and torsade de pointes: recent advances. Curr. Opin. Cardiol., 2007, 22, 39-43.

[56] Yang, P.; Kanki, H.; Drolet, B.; Yang, T.; Wei, J.; Viswanathan, P.C.; Hohnloser, S.H.; Shimizu, W.; Schwartz, P.J.; Stanton, M.; Murray, K.T.; Norris, K.; George, A.L. Jr.; Roden, D.M. Allelic variants in long-QT disease genes in patients with drug-associated torsades de pointes. Circulation, 2002, 105, 1943-1948.

[57] Paulussen, A.D.; Gilissen, R.A.; Armstrong, M.; Doevendans, P.A.; Verhasselt, P.; Smeets, H.J.; Schulze-Bahr, E.; Haverkamp, W.; Breithardt, G.; Cohen, N.; Aerssens, J. Genetic variations of KCNQ1, KCNH2, SCN5A, KCNE1 and KCNE2 in drug-induced long QT syndrome patients. J. Mol. Med. (Berl.), 2004, 82, 182188 .

[58] Kamei, S.; Sato, N.; Harayama, Y.; Nunotani, M.; Takatsu, K.; Shiozaki, T.; Hayashi, T.; Asamura, H. Molecular analysis of potassium ion channel genes in sudden death cases among patients administered psychotropic drug therapy: are polymorphisms in LQT genes a potential risk factor? J. Hum. Genet., 2014, 59, 95-99.

[59] Cheng, J.; Tester, D.J.; Tan, B.H.; Valdivia, C.R.; Kroboth, S.; Ye, B.; January, C.T.; Ackerman, M.J.; Makielski, J.C. The common African American polymorphism SCN5A-S1103Y interacts with mutation SCN5A-R680H to increase late Na current. Physiol. Genomics, 2011, 43, 461-466.
[60] Splawski, I.; Timothy, K.W.; Tateyama, M.; Clancy, C.E.; Malhotra, A.; Beggs, A.H.; Cappuccio, F.P.; Sagnella, G.A.; Kass, R.S.; Keating, M.T. Variant of SCN5A sodium channel implicated in risk of cardiac arrhythmia. Science, 2002, 297, 1333-1336.

[61] Kaab, S.; Crawford, D.C.; Sinner, M.F.; Behr, E.R.; Kannankeril, P.J.; Wilde, A.A.; Bezzina, C.R.; Schulze-Bahr, E.; Guicheney, P.; Bishopric, N.H.; Myerburg, R.J.; Schott, J.J.; Pfeufer, A.; Beckmann, B.M.; Martens, E.; Zhang, T.; Stallmeyer, B.; Zumhagen, S.; Denjoy, I.; Bardai, A.; van Gelder, I.C.; Jamshidi, Y.; Dalageorgou, C.; Marshall, V.; Jeffery, S.; Shakir, S.; Camm, A.J.; Steinbeck, G.; Perz, S.; Lichtner, P.; Meitinger, T.; Peters, A.; Wichmann, H.E.; Ingram, C.; Bradford, Y.; Carter, S.; Norris, K.; Ritchie, M.D.; George, A.L. Jr.; Roden, D.M. A large candidate gene survey identifies the KCNE1 D85N polymorphism as a possible modulator of drug-induced torsades de pointes. Circ. Cardiovasc. Genet., 2012, 5, 91-99.

[62] Bauer, M. RNA in forensic science. Forensic Sci. Int. Genet., 2007, 1,69-74.

[63] Heinrich, M.; Matt, K.; Lutz-Bonengel, S.; Schmidt, U. Successful RNA extraction from various human postmortem tissues. Int. J. Legal Med., 2007, 121, 136-142.

[64] Zhao, D.; Ishikawa, T.; Quan, L.; Michiue, T.; Zhu, B.L.; Maeda, H. Postmortem quantitative mRNA analyses of death investigation in forensic pathology: an overview and prospects. Leg. Med. (Tokyo), 2009, 11, S43-45.

[65] Roy, S.; Sen, C.K. MiRNA in innate immune responses: novel players in wound inflammation. Physiol. Genomics, 2011, 43, 557565 .

[66] Sonkoly, E.; Stahle, M.; Pivarcsi, A. MicroRNAs: novel regulators in skin inflammation. Clin. Exp. Dermatol., 2008, 33, 312-315.

[67] Sen, C.K.; Gordillo, G.M.; Khanna, S.; Roy, S. Micromanaging vascular biology: tiny microRNAs play big band. J. Vasc. Res., 2009, 46, 527-540.

[68] Shilo, S.; Roy, S.; Khanna, S.; Sen, C.K. Evidence for the involvement of miRNA in redox regulated angiogenic response of human microvascular endothelial cells. Arterioscler. Thromb. Vasc. Biol., 2008, 28, 471-477.

[69] Cheng, J.; Yu, H.; Deng, S.; Shen, G. MicroRNA profiling in mid and lategestational fetal skin: implication for scarless wound healing. Tohoku J. Exp. Med., 2010, 221, 203-209.

[70] Vlahou, A.; Fountoulakis, M. Proteomic approaches in the search for disease biomarkers. J. Chromatogr. B Analyt. Technol. Biomed. Life Sci., 2005, 814, 11-19.

[71] Virkler, K.; Lednev, I.K. Analysis of body fluids for forensic purposes: from laboratory testing to non-destructive rapid confirmatory identification at a crime scene. Forensic Sci. Int., 2009, 188, 117.

[72] Tobe, S.S.; Watson, N.; Daeid, N.N. Evaluation of six presumptive tests for blood, their specificity, sensitivity and effect on high molecular-weight DNA. J. Forensic Sci., 2007, 52, 102-109.

[73] Pang, B.C.M.; Cheung, B.K.K. Identification of human semenogelin in membrane strip test as an alternative method for the detection of semen. Forensic Sci. Int., 2007, 169, 27-31.

[74] Quarino, L.; Dang, Q.; Hartmann, J.; Moynihan, N. An ELISA method for the identification of salivary amylase. J. Forensic Sci., 2005, 50, 873-876.

[75] Myers, J.R.; Adkins, W.K. Comparison of modern techniques for saliva screening. J. Forensic Sci., 2008, 53, 862-867.

[76] Godovac-Zimmermann, J.; Brown, L.R. Perspectives for mass spectrometry and functional proteomics. Mass Spectrom. Rev., 2001, 20, 1-57.

[77] Patterson, S.D.; Aebersold, R.H. Proteomics: the first decade and beyond. Nat. Genet., 2003, 33 Suppl, 311-323.

[78] Van Riper, S.K.; de Jong, E.P.; Carlis, J.V.; Griffin, T.J. Mass spectrometry- based proteomics: basic principles and emerging technologies and directions. Adv. Exp. Med. Biol., 2013, 990, 1-35.. 